\title{
O Museu Afro Brasil
}

Emanoel Araujo

Diretor curador.

E-mail: curadoria@museuafrobrasil.com.br

Resumo: Ao longo de mais de trinta anos de trabalho voltado para o resgate da memória do negro no Brasil, o artista plástico, curador e diretor de museus Emanoel Araujo reuniu uma extraordinária coleção de cerca de cinco mil obras, entre pinturas, esculturas, gravuras, fotografias, livros, vídeos e documentos, de artistas e autores brasileiros e estrangeiros, relacionados com a temática do negro. Em 2004, o artista criou o Museu Afro Brasil, com o patrocínio da Petrobras e com parcerias estabelecidas com as secretarias de cultura da cidade e do Estado de São Paulo, bem como com o Ministério da Cultura. Já foram realizados no Museu mais de 80 exposições temporárias, atividades educativas e eventos, que the renderam o reconhecimento de instituição de grande importância no cenário cultural local e nacional.

Palavras-chave: memória, cultura, museu, escravidão, negro.
Abstract: Along more than 30 years of work turned to the recovery of black people memory in Brazil, the fine artist, museums curator and director Emanoel Araujo joined an extraordinary collection of more than 5.000 works, paintings, sculptures, engravings, photographies, books, videos and documents, by Brazilian and foreign artists and authors, related to the theme of black people. In 2004, the artist created the Museu Afro Brasil, sponsored by Petrobras and with partnerships with the São Paulo City and State General Offices of Culture and the Ministry of Culture. The Museum has already carried out more than 80 temporary exhibitions, educative activities and events that brought it the recognition as institution of great importance in the local and national cultural scenery.

Keywords: memory, culture, museum, slavery, black people.

\section{CRIAÇÃO}

Localizado no Parque Ibirapuera, em São Paulo, o Museu Afro Brasil é uma Organização Social de Cultura (Secretaria de Estado da Cultura - Governo do Estado de São Paulo) e foi inaugurado em 23 de outubro de 2004. Com um acervo de cerca de cinco mil obras e uma biblioteca com mais de 6.800 publicações referentes a história, arte e cultura do negro no Brasil, a instituição mantém um sistema de visitação gratuita para todas as exposições. Parte das obras, cerca de duas mil, foi doada pelo artista plástico baiano Emanoel Araujo, idealizador e atual diretor-curador do Museu Afro Brasil.

O Museu dispõe de $11 \mathrm{mil} \mathrm{m}^{2}$, com área expositiva dividida em três ambientes.

Mantendo em exposição aproximadamente $90 \%$ do seu acervo, já realizou cerca de 70 exposições temporárias, atividades educativas e eventos que deram ao Museu o reconhecimento de instituição de grande importância no cenário cultural municipal e nacional. 
comunicação \& educação • Ano XV • Número 1 • jan/abr 2010

\section{UM MUSEU DA DIÁSPORA AFRICANA NO NOVO MUNDO}

O Museu Afro Brasil é resultado de mais de três décadas de pesquisas e exposições, exibindo o negro, quem foi negro e quem é negro no Brasil, de séculos passados aos dias atuais. Registra, preserva e argumenta - a partir do olhar e da experiência da população negra - a formação da identidade brasileira, diante de uma coleção de cerca de 4.500 obras. São pinturas, esculturas, gravuras de artistas brasileiros e estrangeiros, além de fotografias, livros, vídeos e documentos, para delinear um fio condutor desse ambicioso projeto, com algumas premissas definidas, mas ainda com muito a se trabalhar para torná-lo uma realidade consolidada.

No ponto de partida, há a certeza de que não se poderia contar essa história por meio de uma visão oficial escamoteadora, que insiste em minimizar a herança africana como matriz formadora de uma identidade nacional, ignorando a saga de mais de cinco séculos de história e de dez milhões de africanos triturados na construção deste país.

Da perspectiva do negro, este não é um processo exclusivo do Brasil, pois sua presença, aqui como nas Américas, é indissociável da experiência de desenraizamento de milhões de seres humanos graças à escravidão. Assim, assumindo essa perspectiva, o Museu Afro Brasil, por ser um museu brasileiro, não pode deixar de ser também um museu da diáspora africana no Novo Mundo.

É a escravidão que, na diáspora, força o contato e o intercâmbio entre membros de diferentes nações africanas e produz as mais diversas formas de assimilação entre suas culturas e as de seus senhores, bem como de resistência à dominação que tais culturas lhes impõem.

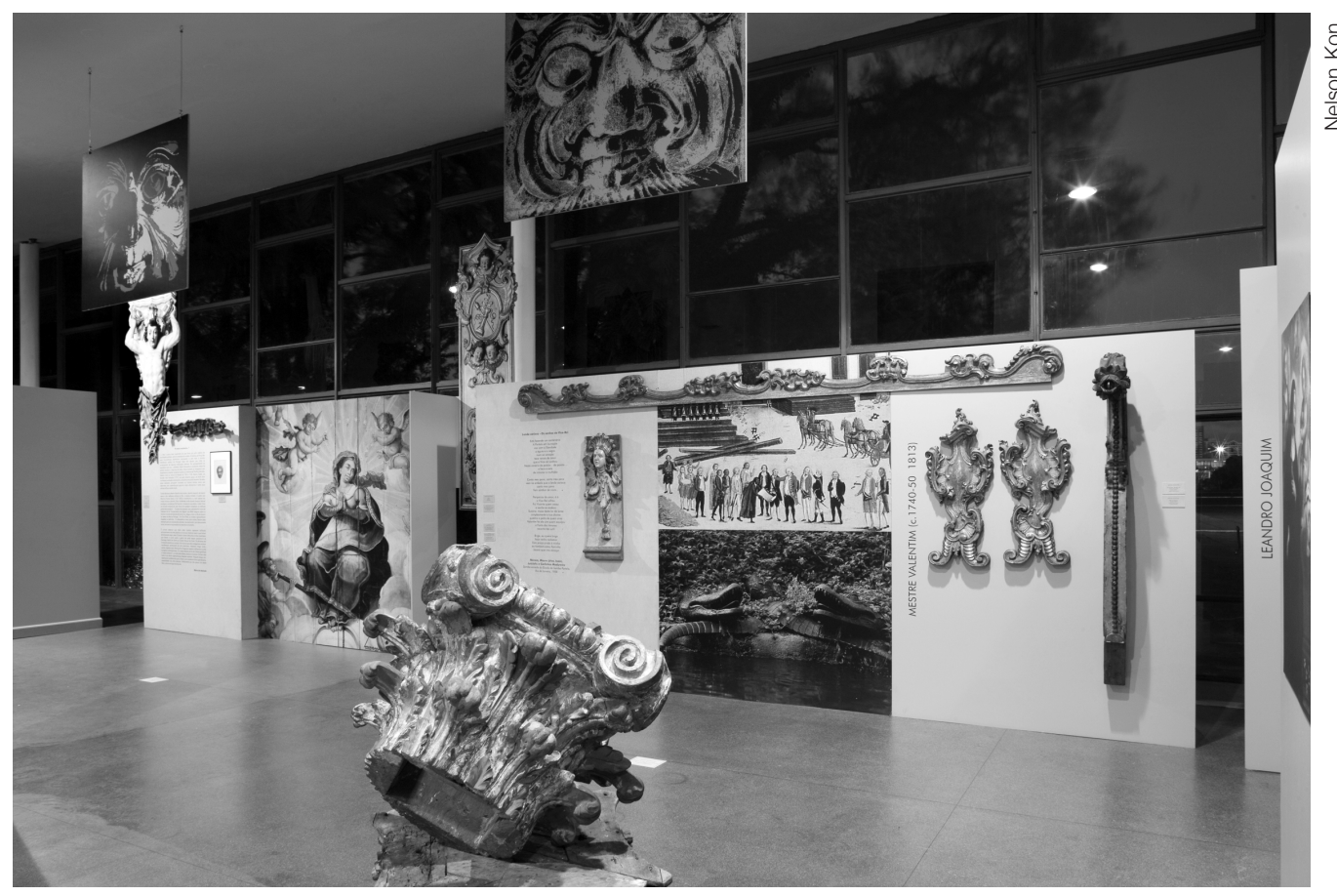

Acervo permanente do Museu Afro Brasil. Arte do s culo XVIII. 
Como um museu da diáspora, o Museu Afro Brasil registra, portanto, não só o que de africano ainda existe entre nós, mas o que foi aqui apreendido, caldeado e transformado pelas mãos e pela alma do negro, salvaguardando ainda o legado de nossos artistas. E foram muitos anônimos e reconhecidos que nesse processo de miscigenação étnica e mestiçagem cultural contribuíram para a originalidade de nossa brasilidade.

Entretanto, não se pode esquecer de que a cultura mestiça que se forma na diáspora envolve relações entre desiguais, em se tratando de senhores e escravos. Da perspectiva do negro, esta é uma história de muito e doloroso trabalho, de incertezas, incompreensões e inconsciências, que ainda hoje persistem na mentalidade de parte da elite brasileira.

Não é só uma história de preconceitos, racismo e discriminação, mas, sobretudo, de exclusão social das mais danosas e permissivas, nesse abismo das desigualdades criadas e cristalizadas no Brasil como herança da escravidão.

\section{MISSÃO}

O Museu Afro Brasil tem como missão precípua a desconstrução de estereótipos, de imagens deturpadas e expressões ambíguas sobre personagens e fatos históricos relativos ao negro, fazendo pairar sobre eles obscuras lendas que um imaginário perverso ainda hoje inspira, e que agem silenciosamente sobre nossas cabeças, como uma guilhotina prestes a entrar em ação cada vez que se vislumbra alguma conquista a qual represente uma mudança ou o reconhecimento da verdadeira contribuição do negro à cultura brasileira.

Este museu une história, memória, arte, cultura e contemporaneidade, entrelaçando essas vertentes num só discurso, para narrar uma heroica saga africana, desde antes da trágica epopeia da escravidão até nossos dias, incluindo todas as contribuições possíveis, os legados, participações, revoltas, gritos e sussurros a que deu lugar, no Brasil e no circuito da diáspora negra.

Um Museu que reflete uma herança na qual, como num espelho, o negro possa se reconhecer, reforçando a autoestima de uma população excluída e com a identidade estilhaçada, e que busca na reconstrução da autoimagem a força para vencer os obstáculos à sua inclusão numa sociedade cujos fundamentos seus ancestrais nos legaram.

O Museu Afro Brasil é, portanto, um museu histórico que fala das origens, mas atento a identificar na ancestralidade a dinâmica de uma cultura que se renova mesmo na exclusão. Um centro de referência da memória negra, que reverencia a tradição que os mais velhos souberam guardar, e reconhece os heróis anônimos de grandes e pequenos combates, e os negros ilustres na esfera das ciências, letras e artes, no campo erudito ou popular. Um museu que expõe com rigor e poesia ritos e costumes que traduzem outras visões de mundo e da história, festas que evidenciam o encontro e a fusão de culturas luso/afro-ameríndias para formar a cultura mestiça do Novo Mundo, mas que 
também registra as inovações da cultura negra contemporânea na diáspora. Um museu de arte, passada e presente, que reconhece o valor da recriação popular da tradição, mas reafirma o talento negro erudito, nas artes plásticas e nas artes cênicas, tanto na música como na dança.

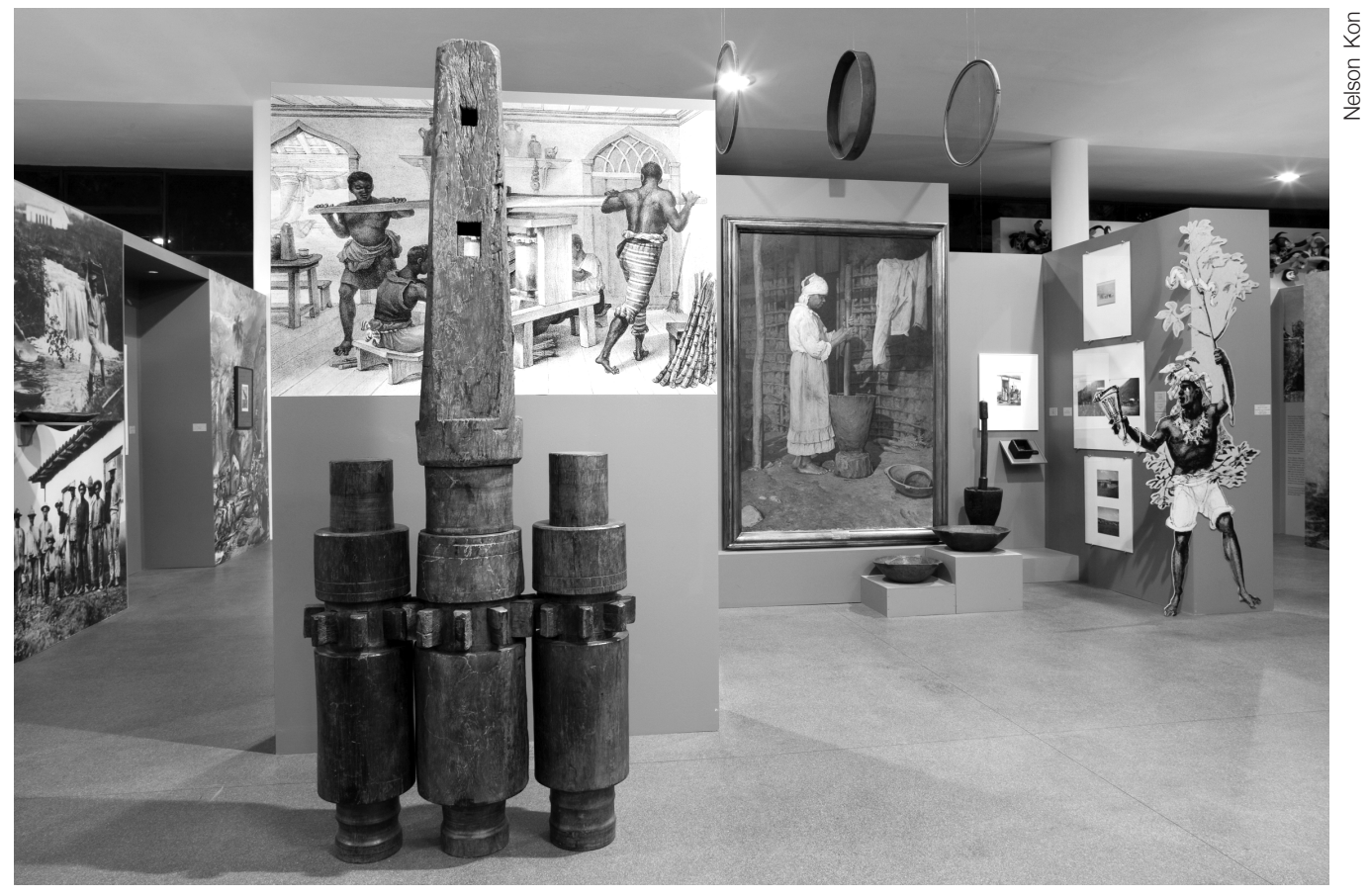

Acervo permanente do Museu Afro Brasil. Tecnologia e design na poca da escravid o.

Sobretudo, o Museu Afro Brasil é contemporâneo, em que o negro de hoje pode se reconhecer. Um museu que integra os anseios do negro jovem e pobre ao seu programa museológico, contribuindo para sua formação educacional e artística, bem como para a formação intelectual e moral de negros e brancos, cidadãos brasileiros, em benefício das gerações que virão. Um museu capaz de colaborar na construção de um país mais justo e democrático, igualitário do ponto de vista social, aberto à pluralidade e ao reconhecimento da diversidade no plano cultural, mas também capaz de reatar os laços com a diáspora negra, promovendo trocas entre a tradição, a herança local e a inovação global.

Um museu que está na maior cidade brasileira e uma das maiores do mundo, e que, por ser ela própria multicultural e multirracial, é o palco ideal para concretizar essa utopia, assumindo uma tarefa pioneira na criação de uma instituição que pode servir como instrumento para se repensar novos conceitos de inclusão social, e espelho para refletir uma sociedade, enfim, disposta a incorporar o outro nas suas diferenças. Afinal, foi nesta cidade de São Paulo que a herança de sangue, suor e lágrimas, de africanos que souberam conservar o patrimônio de sua cultura e memória, ergueu os quilombos do Jabaquara e da Saracura, e gerou personalidades como André Rebouças e Luis Gama, cidadãos negros, heróis brasileiros na luta contra a escravidão. 


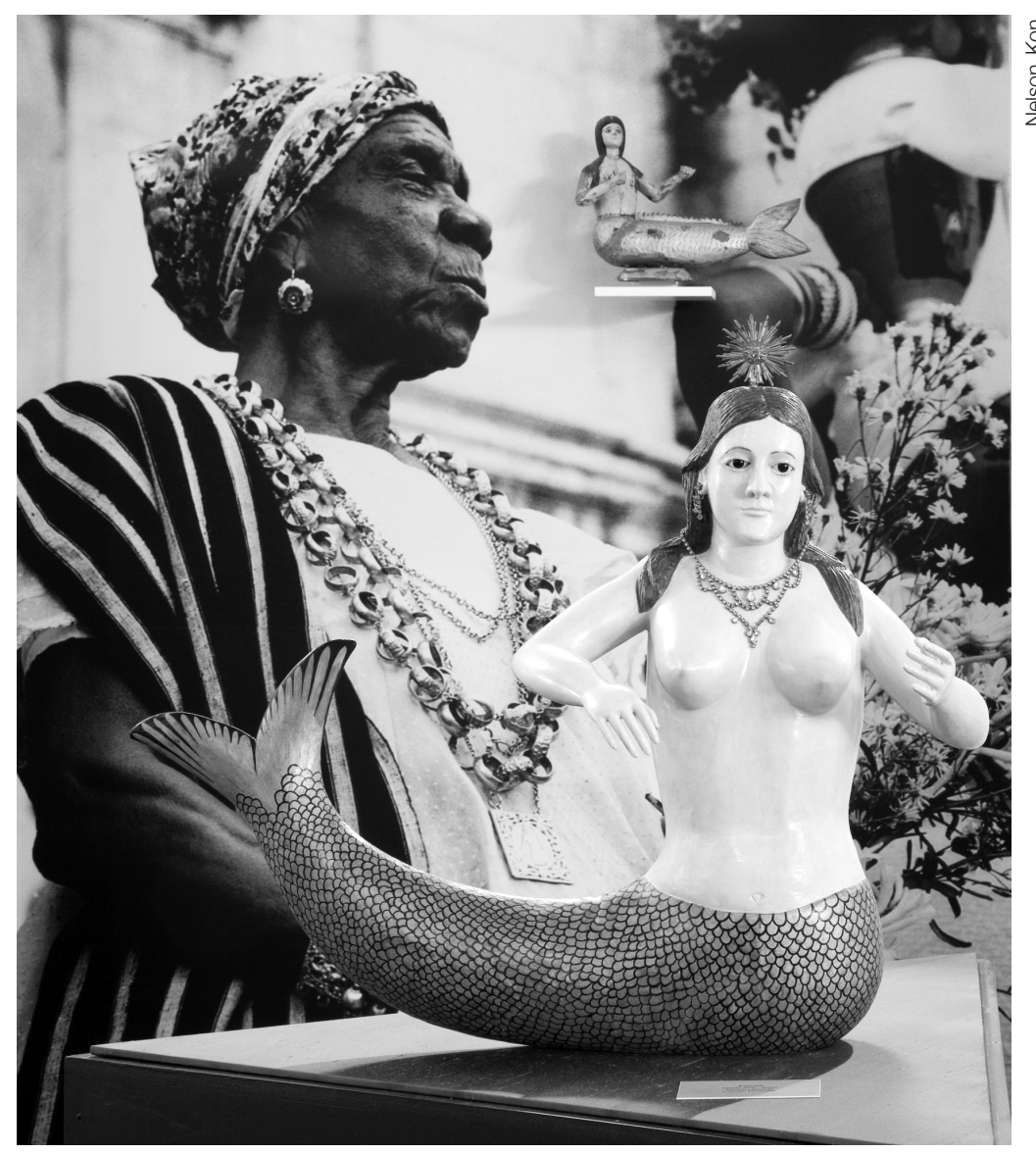

Acervo permanente do Museu Afro Brasil. Sincretismo.

\section{SERVIÇO}

\section{Museu Afro Brasil - Organização Social de Cultura}

Avenida Pedro Álvares Cabral, s/n

Parque do Ibirapuera

CEP 04094-050 - São Paulo-SP

Tel.: (11) 5579-0593

Horário de visitação: de terça-feira a domingo, das $10 \mathrm{~h}$ às $17 \mathrm{~h}$, com permanência até as $18 \mathrm{~h}$. Horário do atendimento administrativo: de segunda-feira a sexta-feira, das $10 \mathrm{~h}$ às $17 \mathrm{~h}$. Agendamentos para visitas orientadas devem ser feitos pelo telefone (11) 5579-0593, no setor de agendamento.

Estacionamento: Portão 3 - Parque Ibirapuera (Zona Azul)

Entrada: Grátis

Informações: (11) 5579-0593

Site: <http://www.museuafrobrasil.com.br>

E-mail: faleconosco@museuafrobrasil.com.br 


\section{Em mutação, indivíduo e sociedade em suas relações com a comunicação, a fé, a teanoloria}

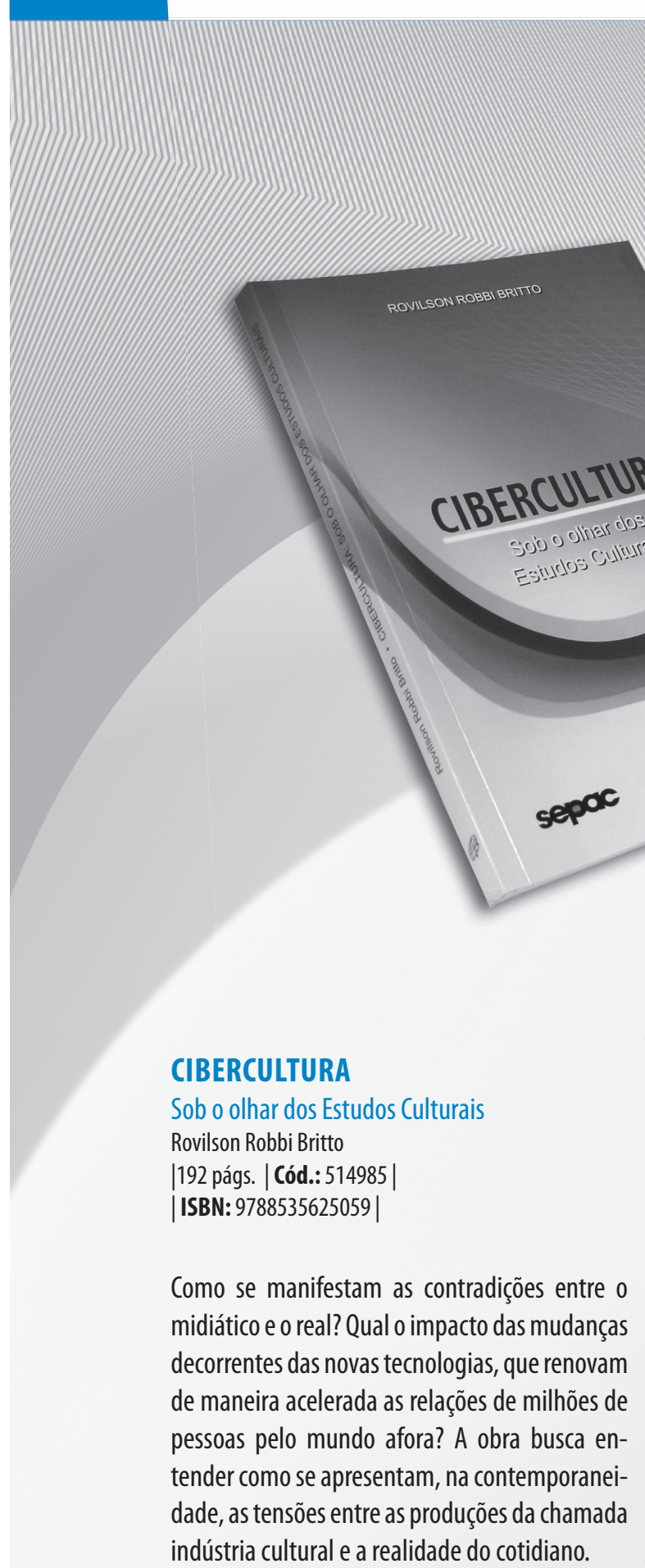

\section{FÉ E CULTURA}

Desafios de um diálogo em comunicação Celito Moro

|104 págs. | Cód.: 516945 |

| ISBN: 9788535626124 |

A questão central desta obra é o desafio que se coloca à Igreja na realização do diálogo entre a fé e a cultura. Partindo da tese de que há uma ruptura entre fé e cultura, e que ambas são fortemente influenciadas pela ciência e pela mídia, Celito sugere à Igreja reaprender a comunicar-se a partir de novos relacionamentos e novos paradigmas, dialogando e buscando a inculturação do Evangelho.

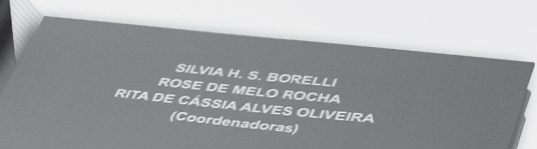
JOVENSNA CENA METROPOLITANA modos de narrativas comunicaçấo 88888888888
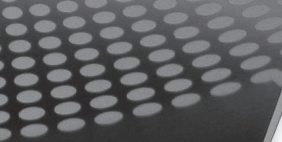
+ Pallinass

\section{JOVENS NA CENA METROPOLITANA}

Percepções, narrativas e modos de comunicação Silvia H. S. Borelli, Rose de Melo Rocha e Rita de Cássia Alves Oliveira (coords.) | 184 págs. | Cód.: 515019| | ISBN: 9788535624557 |

Quais concepções os jovens têm sobre vida e morte e como as relacionam à violência e ao consumo cultural no ambiente urbano? A questão deu origem a extensa pesquisa de campo com jovens entre 15 e 24 anos, moradores em áreas de contraste e exclusão das zonas sul e oeste de São Paulo (SP). A intenção foi analisar as culturas juvenis, seus códigos e suas relações de vida e futuro diante das diferentes mídias e tecnologias. 